\title{
¿LEYES INTERPRETATIVAS INCONSTITUCIONALES?
}

FERNANDO SANTAOLALLA LÓPEZ 
SUMARIO

1. INTRODUCCIÓN: LA STC 31/2010 VUELVE SOBRE DOCTRINA ANTERIOR. 2. LA STC 76/1983, DE 5 AGOSTO. 3. LO QUE DICE LA NUEVA STC 31/2010 SOBRE LAS LEYES INTERPRETATIVAS. 4. NECESIDAD DE INTERPRETACIÓN CONSTITUCIONAL LEGISLATIVA. 5. CONDICIONES DE LA INTERPRETACIÓN CONSTITUCIONAL LEGISLATIVA. 6. QUÉ SUPONE SER INTÉRPRETE SUPREMO DE LA CONSTITUCIÓN. 7. LO QUE RESULTARÍA INCONSTITUCIONAL. 8. INTERPRETACIÓN DEL TRIBUNAL CONSTITUCIONAL NO ES LO MISMO QUE PODER NORMATIVO. 9. SOBRE LA LEGALIZACIÓN DE LA INTERPRETACIÓN DEL TRIBUNAL CONSTITUCIONAL. 


\title{
¿LEYES INTERPRETATIVAS INCONSTITUCIONALES?
}

POR

\author{
FERNANDO SANTAOLALLA LÓPEZ
}

Letrado de las Cortes Generales

Profesor Titular de Derecho Constitucional. Universidad de Alcalá

\section{INTRODUCCIÓN: LA STC 31/2010 VUELVE SOBRE DOCTRINA ANTERIOR}

La STC 31/2010, de 28 de junio, sobre el estatuto de autonomía de Cataluña aprobado por la Ley orgánica 6/2006, está destinada a ser debatida extensa e intensamente. Igual que la materia sobre que recae, este pronunciamiento del Tribunal Constitucional incide en elementos estructurales del Estado, por lo que no puede extrañar que se convierta en centro de interés y referencia obligada durante mucho tiempo.

El presente comentario se inserta desde luego dentro de ese panorama. Sin embargo, no pretendemos abordar los fundamentos de más clara incidencia autonómica o territorial, y que previsiblemente suscitarán más debate, como la declaración de nación y los símbolos nacionales, el régimen lingüístico, las relaciones entre los nuevos poderes autonómicos y los centrales, y otros ejemplos que podrían citarse.

Las líneas que siguen no buscar analizar o criticar los obiter dicta de más relevancia para la estructura territorial del Estado, sino un aspecto que, sin perjuicio de su repercusión autonómica y estatutaria, tiene una particular incidencia en la temática de las fuentes del Derecho y, más en concreto, de la interpretación de la propia Constitución y la posición al respecto del Tribunal Constitucional. Se trata de abordar una cuestión más general, con repercusión en el tema autonómico sin duda, pero en modo alguno ceñido al mismo. 
Nos estamos refiriendo a las llamadas leyes interpretativas, leyes que más que regular una materia se dedicarían a fijar la interpretación correcta de un precepto o norma constitucional. Los fundamentos jurídicos 57 y 58 de la STC $31 / 2010$ abundan en esta materia, con diversos cometarios sobre su licitud y límites, de los que se deducen no menos importantes consecuencias.

Con ello el Tribunal Constitucional recupera una doctrina aparecida con la STC 76/1983, de 5 agosto, dictada en el recurso previo de inconstitucionalidad contra la famosa LOAPA (Ley orgánica de armonización del proceso autonómico). Sorprende esta reaparición en la nueva y trascendente sentencia sobre el Estatuto catalán, dada la razonable crítica que recibió de destacados autores ${ }^{1}$. No obstante, es cierto que la misma había tenido continuidad en otros pronunciamientos, como la STC 247/2007², de 12 de diciembre, dictada en el recurso contra la Ley Orgánica 1/2006, de reforma del Estatuto de Autonomía de la Comunidad Valenciana.

Al igual que esta última, la STC 31/2010 no es innovadora al respecto, sino que se limita a seguir y ampliar lo proclamado en la STC 76/1983.

Estas sentencias plantean cuestiones de mucha sustancia para las fuentes del Derecho y de ahí el interés que han despertado en el autor de este comentario. Aunque dictadas en un contexto de distribución competencial, ambas se pronuncian como luego veremos con una pretensión generalizadora, como si sus conclusiones tuvieran validez para cualquier tipo de legislación. Por eso abordamos el presente examen desde la perspectiva global de las fuentes del Derecho, la posición del legislador y la propia del Tribunal Constitucional.

Junto a consideraciones acertadas, encontramos otras que no nos lo parecen, bien porque se parte de una premisa discutible, bien porque aun partiendo de una indiscutible se realiza un razonamiento no del todo lógico o coherente.

A efectos de una exposición coherente, estimamos oportuno hacer un resumen de la primera y la última de estas sentencias, que son las que nos parecen más relevantes en el tema que nos ocupa, con la exposición de sus argumentos. Luego se procederá a un análisis crítico de las mismas.

${ }^{1}$ Véase SANTIAGO MUÑOZ MACHADO 1983 pág. 132 y ss. y PEDRO CRUZ VILLALÓN edición de 2006 pág. 130 y ss. Como se podrá comprobar, nuestra postura coincide en amplia medida con la de estos autores. Favorable en cambio a la doctrina del Tribunal Constitucional fue la de JAVIER PÉREZ ROYO 1988 pág. 64 y ss.

${ }^{2}$ Véase especialmente su fundamento jurídico 8. Otras sentencias que también recogen esta postura son: STC 227/1988, de 29 de noviembre; 214/1989, de 21 de diciembre; 17/1991, de 31 de enero; 197/1996, de 28 de noviembre; 40/1998, de 19 de febrero, y 15/2000, de 20 de enero. 


\section{LA STC 76/1983, DE 5 AGOSTO}

Dicha sentencia contenía los siguientes pronunciamientos.

En el fundamento jurídico 4 se parte de un postulado que pocos discutirían:

«No cabe duda - y así lo señala el Abogado del Estado — que las Cortes Generales, como titulares «de la potestad legislativa del Estado» (art. 66.2 de la Constitución), pueden legislar en principio sobre cualquier materia sin necesidad de poseer un título específico para ello, pero esta potestad tiene sus límites, derivados de la propia Constitución, y, en todo caso, lo que las Cortes no pueden hacer es colocarse en el mismo plano del poder constituyente realizando actos propios de éste, salvo en el caso en que la propia Constitución les atribuya alguna función constituyente».

A lo que sigue este otro comentario no menos indiscutible:

«Al Tribunal Constitucional corresponde, en su función de intérprete supremo de la Constitución (art. 1 de la LOTC), custodiar la permanente distinción entre la objetivación del poder constituyente y la actuación de los poderes constituidos, los cuales nunca podrán rebasar los límites y las competencias establecidas por aquél».

Pero luego se llega a lo que va ser el meollo de nuestro análisis donde se encuentra este pronunciamiento, a nuestro juicio no tan indiscutible:

"Pero el legislador ordinario no puede dictar normas meramente interpretativas cuyo exclusivo objeto sea precisar el único sentido, entre los varios posibles, que deba atribuirse a un determinado concepto precepto de la Constitución, pues, al reducir las distintas posibilidades o alternativas del texto constitucional a una sola, completa de becho la obra del poder constituyente y se sitúa funcionalmente en su mismo plano, cruzando al hacerlo la línea divisoria entre el poder constituyente y los poderes constituidos.»

Y en el fundamento jurídico 7 se completa esta descripción de las llamadas leyes interpretativas en la forma siguiente:

«Es evidente que cuando el legislador estatal dicta una norma básica, dentro del ámbito de sus competencias, está interpretando lo que debe entenderse por básico en el correspondiente caso concreto, pero, como hemos señalado anteriormente, no cabe confundir esta labor interpretativa del legislador con la producción de normas meramente interpretativas, que fijan el contenido de los términos de la Constitución con carácter general cerrando el paso a cualquier otra interpretación; en este caso el legislador se coloca indebidamente en el lugar que corresponde al poder constituyente y al Tribunal Constitucional ...»

De esta primera aproximación parece deducirse que para el Tribunal Constitucional es lícita la interpretación que realiza el legislador cuando re-

(C) UNED. Revista de Derecho Político

N. ${ }^{\circ}$ 80, enero-abril 2011, págs. 37-58 
gula una materia, pues ciertamente no ignora que todo desarrollo normativo implica una labor interpretativa. Así, antes incluso de las frases reproducidas, ha afirmado:

"Es cierto que todo proceso de desarrollo normativo de la Constitución implica siempre una interpretación de los correspondientes preceptos constitucionales, realizada por quien dicta la norma de desarrollo».

En cambio, la licitud desaparecería cuando esta interpretación consta al margen de toda regulación o desarrollo, cuando se fija el sentido correcto de un precepto constitucional con alcance general. Esto sería lo definitorio de las leyes interpretativas.

\section{LO QUE DICE LA NUEVA STC 31/2010 SOBRE LAS LEYES INTERPRETATIVAS}

La STC 31/2010 prolonga y amplía lo que acabamos de resumir, sin cambios radicales, lo que se revela en la invocación expresa de la STC 76/1983 en su fundamento jurídico 57, párrafo segundo. Acaso puede decirse que lleva más lejos la prohibición de las leyes interpretativas. Pero también cuenta con algún comentario novedoso sobre la posición de la interpretación del propio Tribunal Constitucional.

Su contenido fundamental puede extractarse de la forma siguiente:

«Un límite cualitativo de primer orden al contenido de un Estatuto de Autonomía es el que excluye como cometido de ese tipo de normas la definición de categorías constitucionales.»

De este modo, se mantiene la misma doctrina pero con el matiz de que aquí la limitación interpretativa se contrae a los estatutos de autonomía mientras que en la sentencia anterior la limitación se establecía con carácter general para la legislación.

En cualquier caso la nueva STC ofrece inmediatamente un ejemplo de que lo que, en virtud de lo anterior, quedaría excluido:

«... qué sea legislar, administrar, ejecutar o juzgar, cuáles son los términos de relación entre las distintas funciones normativas y los actos y disposiciones que resulten de su ejercicio; cuál el contenido de los derechos, deberes y potestades que la Constitución erige y regula son cuestiones que, ..., no pueden tener otra sede que la Constitución formal, ni más sentido que el prescrito por su intérprete supremo». 
Poco después abunda en la misma explicación:

"Qué haya de entenderse por competencia y qué potestades comprenda la legislativa frente a la competencia de ejecución... son presupuestos de la definición misma del sistema en el que el Ordenamiento consiste y, por tanto, reservados a la Norma primera que lo constituye».

Es aquí donde se cita la STC 76/1983 en el sentido de que lo anterior responde al «sentido profundo de la distinción entre poder constituyente y poder constituido».

Todo ello desemboca en un pronunciamiento de alcance sobre la posición y función del Tribunal Constitucional y, en concreto, sobre su función interpretativa suprema:

«En su condición de intérprete supremo de la Constitución, el Tribunal Constitucional es el único competente para la definición auténtica —e indiscutible — de las categorías y principios constitucionales. Ninguna norma infraconstitucional, justamente por el hecho de serlo, puede hacer las veces de poder constituyente prorrogado o sobrevenido, formalizando uno entre los varios sentidos que pueda admitir una categoría constitucional».

Más novedad (fundamento jurídico 58) ofrece la postura contraria a que la ley, en el caso el estatuto de autonomía, pueda acomodarse a la previa doctrina del Tribunal Constitucional sobre distribución de competencias:

"Que el Estatuto se acomode efectivamente a tales soluciones ... no resuelve las objeciones de inconstitucionalidad de las que se le hace objeto, toda vez que ... la censura que en realidad merecería no sería tanto la de desconocer las competencias del Estado, cuanto la de bacerse con la función más propia del Tribunal Constitucional, al que se habría cuidado de respetar ateniéndose al sentido de su jurisprudencia, pero olvidando que al formalizar como voluntad legislativa la sustancia normativa de ésta, la desposee de la condición que le es propia en tanto que función jurisdiccional reservada a este Tribunal como intérprete supremo de las normas constitucionales».

Finalmente, puede completarse este resumen con la transcripción siguiente:

«Pueden los Estatutos de Autonomía relacionar sin definir, esto es, sin otro ánimo que el descriptivo de una realidad normativa que le es en sí misma indisponible ... las potestades comprendidas en las competencias atribuidas, en el marco de la Constitución, a las respectivas Comunidades Autónomas».

\section{NECESIDAD DE INTERPRETACIÓN CONSTITUCIONAL LEGISLATIVA}

Yendo de lo más general a lo más concreto podemos abordar la doctrina del Tribunal Constitucional sobre la interpretación constitucional. 
Según hemos visto, esa interpretación por el legislador sería legítima cuando se desarrolla o regula una materia, especialmente en aplicación de la propia Constitución. Pero estaría vedada al margen de la misma, esto es, cuando la ley se limita a interpretar enunciados constitucionales fuera de un marco regulador. Aunque en unos términos no muy claros, donde se yuxtaponen argumentos razonables con otros que no lo son, creemos que ésta es en esencia la doctrina que proclaman ambas sentencias del Tribunal Constitucional.

A veces incluso la prohibición de la que hablamos parece extenderse a la propia regulación de desarrollo. En concreto, recordemos el pasaje antes transcrito: «... el contenido de los derechos, deberes y potestades que la Constitución erige y regula son cuestiones que, ..., no pueden tener otra sede que la Constitución formal, ni más sentido que el prescrito por su intérprete supremo». Esta última manifestación, tomada literalmente, supondría la exclusión, entre otras, de las leyes orgánicas u ordinarias reguladoras de muchos derechos fundamentales del Título I de la Constitución, pues todas ellas abundan en ese contenido que se dice reservar para la ley fundamental y el propio Tribunal Constitucional.

Como esta conclusión no puede aceptarse, pues es inconcebible que el Tribunal haya caído en apreciación tan errónea, ha de asumirse que el inciso en cuestión se ha colado en el cuerpo de la sentencia sin la debida reflexión sobre su alcance. No debe dársele mayor importancia. Pero ello demuestra que ambas sentencias, especialmente la segunda, han realizado pronunciamientos precipitados, simplificaciones excesivas, cuando el terreno sobre el que se movían exigía actitudes muy prudentes.

Pero, aun partiendo de que lo que excluye el Tribunal son las leyes que podemos llamar meramente interpretativas, no la interpretación inherente a toda regulación, la doctrina en cuestión resulta sumamente errónea, producto de una confusa asunción sobre la posición del propio Tribunal.

A nuestro juicio, tan aceptables son las leyes reguladoras o de desarrollo que incorporan una interpretación de las categorías constitucionales como las desnudamente interpretativas ${ }^{3}$. Aunque estas últimas constituyen una categoría harto rara y hasta discutible ${ }^{4}$, en la medida que existan no pueden merecer tan ra-

${ }^{3}$ En sentido análogo PEDRO CRUZ VILLALÓN (2006 pág. 141), que afirma que «el legislador siempre está reduciendo las distintas posibilidades del texto constitucional a una sola y en eso consiste su trabajo».

${ }^{4}$ En Italia se conoce la expresión leyes interpretativas, pero aplicada en un contexto enteramente distinto: se trataría de leyes que interpretan otra ley previa, con la consiguiente duda de si la eficacia de la segunda puede retrotraerse a la entrada en vigor de la primera, la ley interpretada. Para nada se teoriza bajo esta expresión sobre la supuesta imposibilidad de la interpretación constitucional por una ley ordinaria. Véase al respecto, con amplias referencias bibliográficas, ANDREA PUGIOTTO 2003. 
dical exclusión como parece deducirse de ambas sentencias del Tribunal Constitucional ${ }^{5}$.

Comencemos con dos breves ejemplos.

La Constitución se refiere en su artículo 133 a los «tributos». Se trata pues de un concepto o categoría que la Constitución emplea pero que no define. Y es una ley ordinaria, en concreto la Ley General Tributaria (Ley 58/2003, de 17 de diciembre), la que acomete esta función definitoria o interpretativa en su artículo $2^{6}$. Y lo hace con pretensión de fijar el único sentido que en adelante tendrá el término «tributos», sin relación específica con un tributo concreto, sino con propósito generalizador. Con ello se opone a lo que la STC 76/1983 parecía exigir ( $P$ ero el legislador ordinario no puede dictar normas meramente interpretativas cuyo exclusivo objeto sea precisar el único sentido, entre los varios posibles, que deba atribuirse a un determinado concepto precepto de la Constitución»).

Algo parecido se produce con el concepto de «Administración Pública», contemplado en el artículo 103 de la Constitución pero sin llegar a definir lo que se entiende por tal. Ha sido el artículo 2 de la LRJAE-PAC (Ley 30/1992, de 26 de noviembre) la que define o, si se quiere, completa la definición constitucional ${ }^{7}$.

A pesar de esta clara oposición entre la praxis legislativa y la doctrina que comentamos, nadie, que sepamos, ha acusado a ambas leyes de inconstitucionales por extralimitación de sus funciones y, en concreto, por realizar una interpretación o definición de conceptos constitucionales. La conclusión sería que o bien los juristas han pasado por alto en una cuestión clave tan importante doctrina o que la misma incurre en un planteamiento muy defectuoso, ignorando la realidad más elemental.

Pues bien, si esto ocurre con la categoría «tributos» o «Administración Pública», lo mismo puede y debe ocurrir con cualquier otra categoría constitucional. Este es el caso, por sólo mencionar las referidas en las STC 76/1983 y STC 31/2010, de «norma básica», «legislar, administrar, ejecutar o juzgar» 0 «competencia».

\footnotetext{
${ }^{5}$ Véase la perplejidad que también causó esta distinción en SANTIAGO MUÑOZ MACHADO 1983 pág. 133 y ss.

${ }^{6}$ «Los tributos son los ingresos públicos que consisten en prestaciones pecuniarias exigidas por una Administración pública como consecuencia de la realización del supuesto de hecho al que la Ley vincula el deber de contribuir, con el fin primordial de obtener los ingresos necesarios para el sostenimiento de los gastos públicos. Los tributos, además de ser medios para obtener los recursos necesarios para el sostenimiento de los gastos públicos, podrán servir como instrumentos de la política económica general y atender a la realización de los principios y fines contenidos en la Constitución.»

7 «Se entiende a los efectos de esta Ley por Administraciones Públicas: a) La Administración General del Estado. b) Las Administraciones de las Comunidades Autónomas. c) Las Entidades que integran la Administración Local.»
} 
Todos estos conceptos o categorías constitucionales son susceptibles de definición o interpretación en la legislación subconstitucional, tanto cuando regulen una materia en la que inciden esos conceptos como, eventualmente, al margen de la misma. A veces incluso esta interpretación puede resultar ineludible.

Es cierto lo que proclamaba la STC 76/1983: «en todo caso, lo que las Cortes no pueden hacer es colocarse en el mismo plano del poder constituyente realizando actos propios de éste, salvo en el caso en que la propia Constitución les atribuya alguna función constituyente».

Y no menos cierto es lo que seguía:

«Al Tribunal Constitucional corresponde, en su función de intérprete supremo de la Constitución (art. 1 de la LOTC), custodiar la permanente distinción entre la objetivación del poder constituyente y la actuación de los poderes constituidos, los cuales nunca podrán rebasar los límites y las competencias establecidas por aquél».

Igualmente inobjetable es el siguiente pronunciamiento de la STC 31/2010:

«Ninguna norma infraconstitucional, justamente por el hecho de serlo, puede bacer las veces de poder constituyente prorrogado o sobrevenido, formalizando uno entre los varios sentidos que pueda admitir una categoría constitucional».

Un primer error de estas sentencias es considerar que una interpretación legislativa de un concepto o categoría constitucional es ponerse en el mismo plano que el poder constituyente ${ }^{8}$. Y un segundo error es considerar que esta función interpretativa es tarea reservada al Tribunal Constitucional. Veamos ahora ambos aspectos.

\section{CONDICIONES DE LA INTERPRETACIÓN CONSTITUCIONAL LEGISLATIVA}

Repetimos: la interpretación o definición de un concepto, idea o categoría constitucional no equivale necesariamente a colocarse en una función constituyente, a todas luces vedada al legislador ordinario. Para afirmar lo anterior, no hace falta valerse de la teoría de PETER HÄBERLE defensora de un pluralismo interpretativo constitucional, basado en múltiples actores ${ }^{9}$. Basta con la pura

\footnotetext{
${ }^{8}$ En el mismo sentido se manifiesta ENRIQUE ALONSO GARCÍA 1984 pág. 29.

${ }^{9}$ Como es sabido el catedrático alemán ha acuñado el concepto de la sociedad abierta de los intérpretes constitucionales, que precisamente da título a su obra «Die offene Gesellschaft der Verfassungsinterpreten» en JZ, 1975, págs. 297 y s. En español de este autor puede verse 2002 pág. 2749 y ss. Por lo demás, la bibliografía al respecto es inmensa: véase entre otros a DOMINGO GARCÍA BELAUNDE 1994 pág. 33 y ss.
} 
constancia empírica de que el legislador es uno de los intérpretes más característicos de la norma suprema.

En concreto, esa interpretación o definición del legislador será siempre lícita si se observan dos límites básicos.

El primer límite es el significado de las normas constitucionales, que puede ser expreso o tácito. La interpretación o definición legislativa nunca podrá vulnerar o condicionar el recto sentido de las figuras constitucionales, recto sentido que puede constar expresamente o bien deducirse con arreglo a las reglas de la lógica jurídica ${ }^{10}$. Como cualquier actividad aplicativa de la Constitución, su interpretación no puede suponer la alteración o deformación de sus mandatos, categorías o conceptos.

Aunque lo anterior resulta tan obvio que casi eximiría de mayor comentario, procede ahondar ligeramente en el tema para valorar en toda su extensión la doctrina del Tribunal Constitucional.

En este sentido, debe subrayarse que la interpretación o la definición son posibles y hasta necesarias cuando la Constitución no se pronuncia al respecto ${ }^{11}$. El legislador puede concretar el sentido propio de una expresión constitucional cuando la misma carezca de una definición en la propia ley fundamental o, lo que es lo mismo, cuando se presente como una categoría abierta. Si la categoría o concepto constitucional se presentan de este modo, abiertos y sin definición, es porque tácitamente el constituyente quiso que esa función la asumiese la legislación inferior, pues sería absurdo pensar que el constituyente introdujo unos conceptos que malamente podrían utilizarse por falta de definición.

De hecho la STC 11/1981, de 8 de abril, venía a recoger esta idea, al afirmar que la Constitución es un marco de coincidencias suficientemente amplio como para que dentro de él quepan opciones políticas de muy diferente signo ${ }^{12}$.

Por supuesto si la Constitución hubiese definido lo que hubiese de entenderse por «tributos», por «bases» o por «competencias», sobraría la interpretación legislativa posterior o, por lo menos, la misma debería ceñirse a su mera repetición. Pero no es este el supuesto que se maneja, sino el opuesto de ausencia de definición o interpretación por la ley suprema.

${ }^{10}$ Véase al respecto, entre otros, RAUL CANOSA 1987 pág. 7 y ss; JOSÉ ANTONIO GARCÍA AMADO 2004 pág. 69 y ss.

${ }^{11}$ En el mismo sentido SANTIAGO MUÑOZ MACHADO 1983 pág. 134 y ss.

${ }^{12}$ En concreto su fundamento jurídico 7 decía: «La Constitución es un marco de coincidencias suficientemente amplio como para que dentro de él quepan opciones políticas de muy diferente signo. La labor de interpretación de la Constitución no consiste necesariamente en cerrar el paso a las opciones o variantes, imponiendo autoritariamente una de ellas». 
Desde luego resulta totalmente indiferente que la interpretación legislativa conste en una ley reguladora o en una ley que se limita a interpretar. Dejando al margen la ya comentada artificiosidad de esta distinción, pues en la práctica la inmensa mayoría de las leyes contienen ambas facetas, como ocurre precisamente con el Estatuto de Autonomía de Cataluña de 2006, resulta que la Constitución no hace distingo al respecto, lo que vendría a confirmar esa impresión de distinción irreal.

Pero aun admitiendo a efectos discursivos esas dos categorías legislativas, resulta que ambas son leyes que proceden del mismo órgano estatal y, por lo tanto, poseen la misma fuerza de obligar. Por lo que si se admite que una interpretación o definición aparezca en una ley reguladora no otra debe ser la postura respecto al segundo tipo de leyes. Todo ello suponiendo —obvio es decirlo- que han sido tramitadas respetando el procedimiento legislativo.

Repetimos: si las consecuencias jurídicas de ambos tipos de leyes son las mismas - contar con una definición constitucional — su validez o invalidez tendrá que ser la misma, según esa definición vulnere o no a la ley suprema. Lo que es absurdo es afirmar es que una misma definición es inconstitucional por el mero hecho de presentarse aislada de toda regulación pero que es correcta cuando se acompañe de esta última.

El segundo límite que afecta a esta función es que la ley que realiza la interpretación debe resultar disponible, esto es, derogable o modificable por cualquier otra posterior del mismo ámbito y rango. Se produciría el supuesto que denuncia el Tribunal Constitucional, de intentar hacer las veces de un poder constituyente prorrogado o sobrevenido, si esa ley pretendiese vincular ineludiblemente a otras leyes posteriores, lo que se plasmaría en exigir para su reforma requisitos mayores que los dispuestos constitucionalmente, o sea mayoría simple de las cámaras en las leyes ordinarias y mayoría absoluta del Congreso en el caso de las leyes orgánicas. Especialmente se produciría esa subrogación imposible en la función constituyente si la ley reclamase para su reforma los requisitos propios de la reforma constitucional. Pero mientras que no se den esos excesos la ley no sobrepasa el lugar que le corresponde y por tanto su interpretación es perfectamente admisible.

La Ley General Tributaria es constitucional en su interpretación de la categoría «tributos» porque no impide su reforma por el mismo procedimiento que se siguió para su aprobación, esto es, el propio de la ley ordinaria. No sobrepasa su función ni intenta sustituir al poder constituyente. Por eso resulta perfectamente posible desde el punto de vista constitucional —otra cosa sería desde la pura técnica legislativa - que una ley posterior, como la reguladora de un concreto tributo, se separe de su definición. 
La LRJAE-PAC (Ley 30/1992, de 26 de noviembre) define otro concepto constitucional, como es el de «Administración Pública», pero lo hace dentro de su propio ámbito, sin pretender vincular a leyes posteriores, para lo que necesitaría de una superioridad de rango de la que de hecho carece. Por eso las leyes posteriores pueden separarse sin problemas de esta definición. De hecho, el artículo 3 de la Ley de contratos del sector público (Ley 30/2007) contiene una definición no enteramente coincidente. Lo cual demuestra que actuando de esta forma no se asume una posición constituyente o similar, que obviamente resultaría inconstitucional.

Lo mismo puede ocurrir con las categorías mencionadas en las sentencias del Tribunal Constitucional: «norma básica», «legislar, administrar, ejecutar o juzgar» o «competencia». Mientras que la ley que incluya su definición lo haga a los efectos de su aplicación, sin impedir que cualquier otra ley posterior competente por razón de rango o materia pueda cambiar de criterio, tal actuación no es objetable constitucionalmente. Podrá ser criticada desde la perspectiva de la coherencia del ordenamiento jurídico, desde la pura técnica legislativa, pero en sí misma no incurre en vicio de inconstitucionalidad. Pues es precisamente su presentación como ley ordinaria u orgánica, reformable por otra posterior del mismo rango, la que impide hablar de que la misma se sitúe en el mismo plano del poder constituyente ${ }^{13}$.

De este modo, la famosa LOAPA pudo ser inconstitucional por diversos motivos, como presentarse como ley orgánica no debiendo pasar de ordinaria, por invadir materias reservadas a los estatutos de autonomía, por la improcedencia de su condición armonizadora, etcétera. Pero lo que a nuestro juicio era claro es que la misma no pretendió ni pudo subrogarse en la posición del poder constituyente, pues la misma jamás impidió su posibilidad de ser reformada por los mismos cauces observados para su aprobación.

En sentido parecido podemos afirmar que las definiciones del Estatuto de Autonomía de Cataluña no debieran declararse inconstitucionales si se cumplen estas dos condiciones: 1) no oponerse a lo que consta o quepa deducir razonablemente de la propia Constitución y 2) no prejuzgar ni limitar lo que otras leyes puedan disponer al respecto (por ejemplo, un nuevo estatuto de autonomía catalán u otro estatuto para otra Comunidad Autónoma).

${ }^{13}$ Otro ejemplo: el artículo 2 de la Ley 39/2006, de 14 de diciembre, de Promoción de la Autonomía Personal y Atención a las personas en situación de dependencia, define lo que se entiende por «autonomía», pero lo hace a sus propios efectos, que son los del tratamiento de las personas en situación de dependencia. Pero esto naturalmente no excluye que otra ley fije un sentido distinto del término autonomía, como puede ser en materia político- territorial. 


\section{QUÉ SUPONE SER INTÉRPRETE SUPREMO DE LA CONSTITUCIÓN}

Como decimos, toda ley como toda norma puede conllevar una interpretación de una norma superior, esto es interpretación de la Constitución.

Sin embargo, el Tribunal Constitucional con una actitud hipervalorativa de su propia función parece pretender la exclusividad al efecto. Recuérdese entre otros el siguiente pasaje de la STC 31/2010:

«En su condición de intérprete supremo de la Constitución, el Tribunal Constitucional es el único competente para la definición auténtica — e indiscutible - de las categorías y principios constitucionales. Ninguna norma infraconstitucional, justamente por el becho de serlo, puede hacer las veces de poder constituyente prorrogado o sobrevenido, formalizando uno entre los varios sentidos que pueda admitir una categoría constitucional».

Como se ve, el Tribunal Constitucional se atribuye la definición auténtica del texto constitucional. De este modo se ignora lo que constituye la interpretación auténtica de una norma, que no es otra que la aportada por el autor de la misma, normalmente a través de una segunda norma ${ }^{14}$. O sea, en el caso, interpretación auténtica de la Constitución no sería otra que la introducida por el propio constituyente, por supuesto acudiendo al procedimiento de reforma constitucional. En sentido riguroso interpretación constitucional auténtica supondría una reforma constitucional destinada a definir, interpretar o aclarar cualquier concepto o norma existente en su texto. En cambio, en el inciso transcrito es el Tribunal el que parece querer subrogarse en esta posición, que es tanto como asumir la condición de poder constituyente constituido, justo lo que imputa indebidamente al legislador ${ }^{15}$.

El Tribunal Constitucional basa su aserción en el hecho de que el artículo 1 de la LOTC le atribuye la «función de intérprete supremo de la Constitución». De esa definición parece deducirse la imposibilidad de que el legislador realice interpretación de las normas constitucionales, al menos interpretación en estado puro.

${ }^{14}$ Como afirma ANDREA PUGIOTO, interpretación legislativa auténtica no es otra cosa que un acto legislativo y acto de poder. Véase 2003 pág. 192 y ss. También sobre el tema y con amplias referencias bibliográficas sobre las leyes interpretativas puede verse SANTIAGO MUÑOZ MACHADO 1983 pág. 136 y ss.

${ }^{15}$ RICARDO GUASTINI (1998 pág. 34 y ss.) parece admitir como interpretación auténtica constitucional tanto la derivada de la reforma constitucional como la operada por un tribunal constitucional que tenga la última palabra. Pero en contra de lo que argumenta en este último sentido dicho órgano no tiene la última palabra, pues al menos teóricamente cabe que su interpretación resulte corregida por la primera vía. Por importante que sea, el Tribunal Constitucional no es un alter ego del poder constituyente constituido. 
Sin embargo ese principio (por lo demás legal, no propiamente constitucional) no puede significar ni que la interpretación del Tribunal Constitucional posea la condición de auténtica ni que sea la única posible. Ya hemos razonado sobre la normalidad de la interpretación constitucional legislativa, por lo que no insistiremos al respecto.

A nuestro juicio, el problema arranca con una defectuosa interpretación de esa definición del artículo 1 de la LOTC, que por lo demás no ponemos en duda. A nuestro juicio, lo importante de esta definición está más en el adjetivo que en el sustantivo, más en «supremo» que en «intérprete». Lo que se ha querido garantizar es que su interpretación sea suprema, esto es, superior e inapelable, que se impone a cualquier otra que pueda existir. Pero, como también reconoce PEDRO CRUZ VILLALÓN $^{16}$, en modo alguno se pretende que la interpretación de tan alto y cualificado tribunal sea la única, sencillamente por que esto sería imposible ${ }^{17}$.

Lo que supone la definición de intérprete supremo de la Constitución es que sobre la interpretación de las Cortes prevalecerá la del Tribunal Constitucional. Y esa prevalencia se producirá cuando se controle la constitucionalidad de la ley portadora de la interpretación de que se trate.

Lo que a su vez supone que esa ley ha sido impugnada o cuestionada a través de los cauces oportunos ante el Tribunal Constitucional. Aunque suprema y vinculante, la interpretación de este último es dependiente del ejercicio de alguna de las acciones procesales recogidas en la LOTC. Al revés que el legislativo, el Tribunal Constitucional no goza de iniciativa al respecto, no puede por sí mismo y al margen de un recurso o cuestión de inconstitucionalidad manifestarse sobre la interpretación de un concepto constitucional. Esto demuestra que, por importante y trascendente que sea su función, el Tribunal tampoco es un sucedáneo o sustituto del poder constituyente $^{18}$. Se equilibra con el poder legislativo en una relación de peso-contrapeso que contribuye a la estabilidad del Estado constitucional ${ }^{19}$.

${ }^{16}$ Véase 2006 pág. 147.

${ }^{17}$ También MANUEL MEDINA GUERRERO afirma (2001 pag. 76 y ss.) que la interpretación constitucional no es exclusiva del Tribunal Constitucional, sino compartida con el conjunto de tribunales ordinarios. Pero en el punto relativo a la interpretación legislativa parece aceptar la tesis subyacente en la STC 76/1983.

Por su parte, IGNACIO ARANGUREN PÉREZ (2010 pág. 138), sin entrar en la particular cuestión abordada en este trabajo, defiende que la condición de intérprete supremo del Tribunal Constitucional supone que sus decisiones vinculan a los demás órganos del Estado.

${ }^{18}$ Como escribió KONRAD HESSE (1992 pag. 33 y ss.) al tribunal constitucional solo le corresponde frente al legislador una función de control, y le está vedada una interpretación que condujese a una restricción de la libertad conformadora del legislador. También sobre el tema puede verse VICTOR FERRERES 2007 pág. 40.

${ }^{19}$ MIGUEL REVENGA parece criticar la inflación de la función de la justicia constitucio- 
En todo caso, si la interpretación parlamentaria plasmada en la ley respeta los dos límites antes citados, la misma resultará constitucional y por tanto el Tribunal Constitucional deberá reconocerlo así. Con ello queda claro que el mero hecho de interpretar no puede ser en sí mismo objeto de sanción. Por el contrario, si el Tribunal apreciase alguna incorrección de esa interpretación podrá declararlo, anulando el precepto correspondiente. Así se manifiesta la condición de «intérprete supremo» del Tribunal Constitucional, no en el hecho de que no puedan existir leyes interpretativas.

Naturalmente, la apreciación de incorrección puede darse tanto cuando la interpretación legislativa lesione o se aparte del recto sentido de las normas constitucionales, como cuando se separe de una previa interpretación de las mismas por el Tribunal. En ambos casos es factible acudir a los mecanismos impugnatorios de la LOTC, abriéndose paso a que el Tribunal imponga su interpretación, justamente calificada de suprema.

\section{LO QUE RESULTARÍA INCONSTITUCIONAL}

Lo que sí resultaría inconstitucional por contrariar el papel del Tribunal Constitucional sería que la ley apareciese como inmune a su fiscalización. Sería entonces cuando la ley encarnaría un imposible poder constituyente prorrogado o sobrevenido, justamente criticado en la STC de referencia. Pero esa pretendida inmunidad solo podría darse si la misma se presentase como Constitución misma. Esto es, si apareciese como formando parte de la de ley suprema sin haberse sujetado al procedimiento de reforma constitucional. Solo entonces se produciría el supuesto denunciado por el Tribunal. Mientras que la ley no incurra en supuesto tan extremo e imprevisible será controlable por el mismo, y no podrá ser acusada de subversión tan grave.

Naturalmente la ley sería propiamente Constitución si se hubiese aprobado siguiendo el procedimiento del título X de la Constitución. Entonces - fuera de las objeciones de procedimiento que en su caso se pudiesen formular- la misma quedaría fuera del poder de control del Tribunal Constitucional y su interpretación sería inobjetable. Se trataría de una interpretación auténtica, de la aportada por el poder constituyente (constituido). En ese supuesto habría aparecido este último poder, pero esta vez de modo inapelable. Pues como es lógico - y el tribunal no discute - el control de constitucionalidad no puede operar sobre la

nal. En sentido parecido a lo que se acaba de defender, aboga por un diálogo no coercitivo entre el legislador y el titular de dicha justicia. Véase 2005 pag. 154 y sig. 
Constitución misma. La Constitución es la referencia o parámetro al servicio del cual surge el tribunal. Pero sobre ella no ejerce ningún control. El mismo artículo 1 de la LOTC afirma que "está sometido sólo a la Constitución y a la presente Ley Orgánica» ${ }^{20}$.

\section{INTERPRETACIÓN DEL TRIBUNAL CONSTITUCIONAL NO ES LO MISMO QUE PODER NORMATIVO}

Recordemos el siguiente inciso:

«... la censura que en realidad merecería no sería tanto la de desconocer las competencias del Estado, cuanto la de hacerse con la función más propia del Tribunal Constitucional, al que se habría cuidado de respetar ateniéndose al sentido de su jurisprudencia, pero olvidando que al formalizar como voluntad legislativa la sustancia normativa de ésta, la desposee de la condición que le es propia en tanto que función jurisdiccional reservada a este Tribunal como intérprete supremo de las normas constitucionales»

Dos puntos llaman particularmente la atención. Por un lado, que se hable de sustancia normativa de la jurisprudencia de tan alto tribunal, con la consiguiente deducción de que el mismo posee capacidad normativa. Nadie discutirá la importancia de esa jurisprudencia, que como hemos visto adquiere la condición de interpretación suprema, con las consecuencias ya advertidas. Pero de ahí no debería darse el salto a afirmar su naturaleza normativa, pues en modo alguno la Constitución se la atribuye. El Tribunal Constitucional posee un altísimo e insustituible valor como garante de la Constitución, pero no es ni debe ser órgano normativo. Se trata de otra frase escrita con excesiva precipitación, sin el rigor que sería de esperar.

\section{SOBRE LA LEGALIZACIÓN DE LA INTERPRETACIÓN DEL TRIBUNAL CONSTITUCIONAL}

Por otro lado, y acaso esto es lo más importante, en la frase acotada se produce una oposición a que el legislador asuma como propia la jurisprudencia del Tribunal. A nuestro juicio, no se comprende en absoluto esta oposición. Antes al

${ }^{20}$ En el mismo sentido el artículo 27 de la LOTC añade: «... el Tribunal Constitucional garantiza la primacía de la Constitución y enjuicia la conformidad o disconformidad con ella de las leyes, disposiciones o actos impugnados». 
contrario es algo que debería verse como positivo. Si la interpretación del Tribunal Constitucional es suprema, lejos de existir inconveniente, es plausible que la misma adquiere toda la fuerza de la ley que solo la voluntad del Parlamento puede proporcionar. Sería entonces cuando esa interpretación adquiriría fuerza normativa en sentido estricto.

Eso sí, esa objetivación legislativa de la jurisprudencia constitucional podrá ser objeto a su vez de una fiscalización a través de los cauces de la LOTC. Y en ese momento el Tribunal Constitucional podrá determinar si esa nueva regulación receptora de su doctrina se adecua o no a la Constitución o, como dijimos antes, si realmente se adecua a su doctrina.

Es más, esa posibilidad de legislar sobre la interpretación del defensor de la Constitución puede resultar necesaria para no petrificar el ordenamiento jurídico. Es la forma de permitir la evolución de la propia interpretación del Tribunal Constitucional y de la propia legislación. La nueva ley podrá ser fiel a su previa interpretación o doctrina o, por el contrario, podrá apartarse de la misma. Si fuese impugnada por este segundo motivo, el Tribunal Constitucional tendría una oportunidad de revisar su doctrina previa, bien para confirmarla, bien para separarse de la misma en mayor o menor medida. En el primer caso obviamente declararía la inconstitucionalidad de la ley; en el segundo por el contrario podría la daría por válida. En ambos casos, su interpretación se impone como suprema, respetándose así la definición del artículo 1 de la LOTC.

En coincidencia con lo defendido por el magistrado RODRÍGUEZ BEREIJO $^{21}$, creemos que la interpretación del Tribunal Constitucional no debe ser algo petrificado o inmodificable, sino sujeto a posibles evoluciones. Con ello no defendemos el cambio arbitrario u oportunista de criterio, sino simplemente la posibilidad de separarse de la misma cuando hechos concluyentes muestren su limitación o que otro criterio satisface mejor las necesidades sociales.

Si todo cuerpo jurídico tiene su procedimiento de adaptación o reforma, comenzando por la propia Constitución, revisable a través de los procedimientos de su Título X, también la jurisprudencia debe tener su cauce al efecto. Y en el caso de la jurisprudencia constitucional no se nos alcanza otro que el que se acaba de describir, o sea, nueva ley que incide en la doctrina sentada por el Tribunal Constitucional con ocasión de otra ley anterior. El cambio legislativo es el cauce que permite la evolución de esta doctrina.

El Tribunal Constitucional está sometido y debe defender la Constitución, pero su previa doctrina no forma parte estricta de la misma y por eso no merece la misma protección. Su reforma no puede sujetarse a la misma exigencia, tanto por razones lógicas, de inferioridad de rango, como funcionales, de necesidad de un mecanismo más flexible y operativo de adaptación. 
Volviendo a la cuestión inicial, prohibir la legalización de una interpretación del Tribunal Constitucional es como poner puertas al campo. Pues, como ya hemos visto, el legislador siempre dispone de la iniciativa legislativa. No existe prohibición de legislar ni control previo de la iniciativa legislativa. Bien o mal el Parlamento siempre puede aprobar una ley que incida en una previa interpretación del Tribunal Constitucional.

Claro está, que el resultado de su obra podrá ser respetuoso con la previa interpretación o discrepante de la misma, en cuyo caso se abre la posibilidad referida más arriba. Esta garantía es indiscutible. Pero también lo es que la doctrina del Tribunal Constitucional no puede permanecer intocable por la legislación.

Ejemplo candente de lo anterior lo tenemos en la última reforma sobre la interrupción del embarazo (Ley Orgánica 2/2010, de 3 de marzo). Ciertamente una de las impugnaciones posibles es que la misma no se ha atenido a la doctrina de la STC 53/1985, dictada respecto a la Ley Orgánica 9/1985 y en la que abundaban indicaciones sobre los casos y forma de licitud de despenalización del aborto. Pero que la ley se ha dictado y que la misma ha operado en medio de esa jurisprudencia resulta indiscutible. Si la ley se excedió por inconstitucionalidad directa o indirecta (o sea vulneración de esa doctrina) podrá ser decidido por el Tribunal Constitucional, siendo lo deseable que se produzca en el plazo más rápido posible. Pero no menos indiscutible nos resulta el derecho del legislativo a regular una materia en la que incide esa jurisprudencia constitucional. Lo contrario sería maniatar al órgano de representación del soberano e impedir la evolución jurídica, consustancial a la vida humana.

\section{BIBLIOGRAFÍA CONSULTADA}

ALDUNATE LIZANA, Eduardo, Interpretación, valores y sistema constitucional, Cuadernos de Derecho Público, INAP, Madrid, 2002

ALONSO GARCÍA, Enrique, La interpretación de la Constitución, CEC, Madrid, 1084

ANZON, Adele, Le leggi di interpretazione autentica tra Corte Costituzionale e Legislatore, Quaderni Della Rivista di Diritto Costituzionale, Torino, 2001

ARAGÓN REYES, Manuel, La interpretación de la Constitución y el carácter objetivado del control jurisdiccional, Revista Española de Derecho Constitucional, 1986

ARANGUREN PÉREZ, Ignacio, Comentarios a la Ley orgánica del Tribunal Constitucional, Dtor.-coord. Juan José González Rivas, La Ley, Madrid, 2010

BALAGUER CALLEJÓN, María Luisa, Interpretación de la Constitución y ordenamiento jurídico, Tecnos, Madrid, 1997 
CANOSA USERA, Raúl, Algunos aspectos problemáticos en la interpretación de la Constitución española, Revista de la Facultad de Derecho de la Universidad Complutense, Madrid, 1989

CASCAJO, José Luis, Constitución e interpretación constitucional, Claves de Razón Práctica, 2003

CRUZ VILLALÓN, Pedro, La curiosidad del jurista persa y otros estudios sobre la Constitución, CEPC, Madrid, 2006

FERNÁNDEZ SEGADO, Francisco, «Reflexiones en torno a la interpretación de la Constitución», en Eduardo Ferrer Mac-Gregor (coord.), Derecho procesal constitucional, Editorial Porrúa Colegio de Secretarios de la Suprema Corte de Justicia de la Nación, México, 2002

FERRERES COMELLA, VÍCTOR, Justicia constitucional y democracia, CEPC, Madrid, 2007

FREIXES SANJUAN, Teresa, Una aproximación al método de interpretación constitucional, Cuadernos de la Cátedra Fadrique Furió Ceriol, Valencia, 1993

GARCÍA AMADO, José Antonio, «La interpretación constitucional», Revista jurídica de Castilla y León núm. 2 febrero 2004

GARCÍA AMADO, Juan Antonio, La interpretación constitucional, Revista Jurídica de Castilla y León, Valladolid, 2004

GARCÍA BELAUNDE, Domingo, «La interpretación constitucional como problema», Revista de Estudios Políticos núm. 86, octubre- diciembre 1994.

GARCÍA BELAUNDE, Domingo, La interpretación constitucional como problema, Revista de Estudios Políticos, 1994

GONZÁLEZ RIVAS, Juan José, La interpretación de la Constitución por el Tribunal Constitucional, Revista de Derecho Procesal, Madrid, 2005

GUASTINI, Ricardo, ¿Peculiaridades de la interpretación constitucional?, Cuadernos Constitucionales de la Cátedra de Fadrique Furió Ceriol, Valencia, 1998

HÄBERLE, Peter, Métodos y principios de la interpretación constitucional. Un catálogo de problemas, en Eduardo Ferrer Mac-Gregor (coord.), Derecho procesal constitucional, Editorial Porrúa Colegio de Secretarios de la Suprema Corte de Justicia de la Nación, México, 2002

HESSE, KONRAD, Escritos de Derecho constitucional, CEPC, Madrid, 1992

MEDINA GUERRERO, Manuel, Comentarios a la Ley orgánica del Tribunal Constitucional, Coord. Juan Luis Parejo Pagés, Tribunal Constitucional BOE, Madrid, 2001

MUÑOZ MACHADO, Santiago, La interpretación de la Constitución, la armonización legislativa y otras cuestiones (La Sentencia del Tribunal Constitucional de 5 de agosto de 1983: asunto LOAPA), Revista Española de Derecho Constitucional, núm. 9, septiembre-diciembre 1983 
PÉREZ ROYO, Javier, Tribunal Constitucional y división de poderes, Tecnos, Madrid, 1988

PRIETO SANCHÍS, Luis, Notas sobre la interpretación constitucional, Revista del Centro de Estudios Constitucionales, 1991

PUGIOTTO, Andrea, La legge interpretativa e i soui giudici, Facoltà Giuridica dell'università di Ferrara, Milán, 2003

REVENGA SÁNCHEZ, Miguel, Notas sobre justicia constitucional e interpretación de la Constitución (o en defensa de la interpretación como diálogo), Teoría y Realidad Constitucional, Madrid, 2005

TEROL BECERRA, Manuel José, Sobre la interpretación de la Constitución y de la Ley en España (1812-1978), Revista del Centro de Estudios Constitucionales, 1993

Title:

INTERPRETATIVE UNCONSTITUTIONAL LAWS?

\section{Summary}

1. Introduction: STC 31/2010 back on previous doctrine. 2. STC $76 / 1983$ of 5 August. 3. What the new STC/2010 says on interpretative laws. 4. Necessity of legislative constitutional interpretation. 5. Conditions of legislative constitutional interpretation. 6. What supposed to be supreme interpreter of the Constitution? 7. What it would be unconstitutional? 8. Interpretation of the Constitutional Court is not the same that normative power. 9. On the legalization of the interpretation of the Constitutional Court.

\section{Resumen}

Se estudia la jurisprudencia del Tribunal Constitucional según la cual las leyes no pueden ser meramente interpretativas de principios o categorías constitucionales. A juicio del autor esta interpretación legislativa, aislada o acompañando a una regulación, es siempre posible si se cumplen dos condiciones elementales: primera respetar el recto sentido de lo dispuesto en la Constitución y segunda que la ley se mantenga como reformable por otra posterior del mismo rango y ámbito. De otra parte, la interpretación del Tribunal Constitucional es suprema, pero no la única. Y el legislador está capacitado para asumirla o integrarla en leyes posteriores. Claro está que sobre la corrección de esta tarea podrá decidir el mismo tribunal si la ley es sometida a su consideración a través de los procedimientos oportunos. 


\begin{abstract}
The aim of this study is to comment two main rulings of the Constitutional Court forbidding that parliamentary acts contain a pure interpretation of the constitutional categories or principles. According to the author's view, this legislative interpretation, in pure terms or as a part of a regulation, is always possible provided two basic conditions are met: first, to respect the full meaning of the constitutional provisions and second that the act admits its amendment through a future act with the same rank and scope. On the other hand, the interpretation by the Constitutional Court is supreme but not unique. And the legislative power is able enough to assume it in future acts. Of course, the Constitutional Court maintains its competence to judge on the correctness of these acts if they are submitted to its judgment through the respective procedures.
\end{abstract}

\title{
Palabras clave:
}

Legislativo, Parlamento, ley interpretativa, Tribunal Constitucional, intérprete supremo

\section{Key words:}

Legislative power, Parliament, interpretative act, Constitutional Court, supreme interpreter 